\title{
СРАВНИТЕЛЬНЫЙ АНАЛИЗ ПРЕДСТАВЛЕНИЙ О НЕРАВЕНСТВЕ ДОХОДОВ У ПОЖИЛЫХ В СТРАНАХ ЕС И РФ: ВЗАИМОСВЯЗЬ ФАКТИЧЕСКОГО И ВОСПРИНИМАЕМОГО НЕРАВЕНСТВА
}

\author{
Фролова Елена Александровна ${ }^{1,2}$, \\ дfrolova_ea@mail.tsu.ru \\ Кашапова Эльмира Рамисовна², \\ elmira@tpu.ru \\ Маланина Вероника Анатольевна², \\ milanskaya@mail.ru \\ Касати Фабио 2 , \\ kasati@tpu.ru \\ 1 Национальный исследовательский Томский государственный университет, \\ Россия, 634050, Томск, пр. Ленина, 36 \\ ${ }^{2}$ Национальный исследовательский Томский политехнический университет, \\ Россия, 634050, Томск, пр. Ленина, 30
}

\begin{abstract}
Фролова Елена Александровна, доктор экономических наук, профессор кафедры экономики Института экономики и менеджмента Национального исследовательского Томского государственного университета; ведущий научный сотрудник Международной научно-образовательной лаборатории технологий улучшения благополучия пожилых людей Национального исследовательского Томского политехнического университета.
\end{abstract}

Кашапова Эльмира Рамисовна, младший научный сотрудник Международной научнообразовательной лаборатории технологий улучшения благополучия пожилых людей Национального исследовательского Томского политехнического университета.

Маланина Вероника Анатольевна, кандидат экономических наук, доцент отделения социальногуманитарных наук Школа базовой инженерной подготовки Национального исследовательского Томского политехнического университета.

Касати Фабио, PhD, ведущий научный сотрудник Международной научно-образовательной лаборатории технологий улучшения благополучия пожилых людей Национального исследовательского Томского политехнического университета.

В статье анализируется отношение населения к неравенству в старшем возрасте в европейских странах и России. Актуальность исследования обусловлена различиями в представлении о неравенстве и фактических его показателях, что оказывает влияние на востребованность государственных инструментов политики выравнивания, особенно старшим поколением. Целью исследования является оценка взаимосвязи фактического и воспринимаемого неравенства у старшего поколения в ЕС и РФ. Методы исследования: метод описательных статистик на выборках 8 волны Европейского социального исследования (ESS-2016) для возрастной группы 60+ лет в России и европейских странах. Для оценки фактического неравенства использовались данные World Inequality Database (2017) и данные ОЭСР (2018). Для оценки взаимосвязи субъективных и фактических показателей неравенства применен корреляционно-регрессионный анализ. Результаты: комплексная оценка восприятия неравенства у пожилых людей в РФ близка к средним значениям по странам ЕС. Между тем существуют отличия от среднеевропейских значений по оценкам равенства возможностей и уровню толерантности к неравенству, обусловленному личными усилиями и возможностями. Про- 
веденные оценки корреляции между фактическими и субъективными показателями неравенства показали, что существует обратная корреляция между оценками стандартов жизни и легитимностью талантов и усилий, коэффициентом Джини и показателем уровня жизни (GDP per capita). Показатели фактического неравенства демонстрируют тесную прямую связь с рисками бедности пожилых людей. Не выявлена статистически значимая взаимосвязь дифференциации доходов и комплексной оценки восприятия неравенства.

Ключевые слова: Неравенство доходов, пожилые люди, фактическое неравенство, воспринимаемое неравенство, ЕС, РФ.

\section{Введение}

Неравенство и бедность - предмет научных дискуссий с момента становления экономической науки. Особый интерес к этой проблематике, несмотря на объективно достигнутые успехи в области укрепления социальной справедливости и солидарности в рамках реализации принципов государства всеобщего благосостояния, возник в последние несколько лет. С одной стороны, этот интерес обусловлен объективными процессами усиления имущественной и доходной дифференциации как в развивающихся, так и, что более важно, в развитых странах. Эпоха «всеобщего равенства» после Второй мировой войны сменилась периодом усиления конфликтов и противоречий между общественными группами, социальными стратами, странами и регионами, обусловленных ростом неравенства. В первую очередь речь идет о росте неравенства в сфере распределения результатов (доходное и имущественное неравенство). Обеспечение равенства шансов (равенства возможностей), а также социальная мобильность становятся важными факторами укрепления социальной солидарности и стабильности [1].

Другой важный аспект в изучении неравенства в современной экономике - это исследование того, как каждый конкретный человек оценивает неравенство, считает ли он, что неравенство излишне велико или, наоборот, допустимо [2], каковы причины фактически сложившегося уровня неравенства (легитимные и нелегитимные неравенства), что обусловливает запрос на инструменты перераспределения и создает не только экономическую повестку оценки влияния неравенства на базовые макро- и микроэкономические индикаторы, но и политическую повестку, т. к. определяет соотношение политических сил и востребованность социальных программ, направленных на преодоление избыточного неравенства и повышение качества жизни, особенно представителей социально незащищенных слоев населения (бедных, многодетных, пенсионеров, мигрантов, инвалидов и др.) [3, 4].

Ошибки и противоречия в индивидуальных оценках фактического неравенства выявлены в работах нескольких авторов $[5,6]$. В исследованиях отмечается недооценка/переоценка фактического неравенства у представителей различных социальных групп. Авторы высказывают гипотезы о влиянии перспектив социальной мобильности и туннельного эффекта А. Хиршмана.

Зависимость фактического и воспринимаемого неравенства представлена в работе [7]. На основе данных Евробарометра на страновом уровне авторы выявили высокую корреляцию $(0,62)$ между степенью толерантности к неравенству респондентов ЕС и запросом на государственные инструменты перераспределения, которые могут использоваться для преодоления избыточного неравенства. Зависимость между фактическим неравенством (Индексом Джини) и оценками неравенства по результатам исследований акторов оказалась менее сильной $(0,104)$. Более сильная взаимосвязь была выявлена между восприятием неравенства и квинтильным коэффициентом распределения доходов $(0,133)$, оценками неравенства и риском бедности $(0,244)$. Также была проведена 
оценка взаимосвязи фактического неравенства и спроса на инструменты перераспределения на страновом уровне. Выявлена сильная взаимосвязь между показателями бедности и запросом на инструменты перераспределения. Таким образом, в представлениях респондентов более значимыми являются не просто субъективные оценки неравенства, а именно оценки бедности как предиктор запроса на государственную политику выравнивания. Сравнивая представления о неравенстве молодежи (14-25 лет) и пенсионеров (старше 55 лет), авторы выявили более высокий уровень толерантности к неравенству среди молодежи, что подтверждает гипотезу о перспективах социальной мобильности и гипотезу о влиянии перспектив будущего на лояльность к неравенству.

Межстрановые сравнения восприятия неравенства в РФ и КНР проведены в работе Е. Даниловой [8]. Восприятие неравенства оценивалось через значимость ценностей равенства.

В исследовании восприятия неравенства в развивающихся странах и странах Латинской Америки [9] на страновом уровне в сравнительной характеристике социальных групп выявлены существенные трудности в доступе к данным, которые позволяют провести оценку восприятия неравенства. Установлено, что в большинстве рассмотренных стран фактический уровень неравенства значительно выше, чем в странах ОЭСР с самой высокой дифференциацией доходов. Существенное значение в объяснении высокого уровня фактического неравенства имеют оценки гендерного неравенства, неравенство доступа к качественным услугам образования и здравоохранения, неравенство на рабочем месте.

Глобальные изменения реального дохода за 30 лет (1988-2008), выявленные в работах Б. Милановича $[10,11]$, свидетельствуют о высоких темпах роста реального благосостояния у самых необеспеченных слоев населения (1-4 дециль) и самых обеспеченных слоев населения (9-10 дециль), в то время как средний класс (5-8 дециль) не получил существенного прироста благосостояния за этот период, что позволяет говорить, с одной стороны, о росте фактического неравенства в мире, а с другой - о необходимости изменения подходов к оценке фактического неравенства, так как традиционные индикаторы (индекс Джини) не в полной мере отражают происходящие изменения.

Оценки восприятия неравенства, сделанные на основе опросов Фонда общественного мнения в РФ, демонстрируют существенные различия в представлениях россиян о неравенстве и фактическом положении дел в этой сфере [12]. Более $40 \%$ респондентов считают, что в сравнении со странами Европы, российское общество является более справедливым, при этом наблюдается кардинальное изменение восприятия неравенства в РФ с 2011 по 2017 год. В рамках оценки различий в представлениях о равенстве/справедливости у респондентов разных возрастных групп наблюдается тенденция роста уверенности в справедливости российского общества с увеличением возраста респондентов. Если респонденты 18-30 лет выражают серьезные сомнения в оценках справедливости общественного устройства в разных странах, то $47 \%$ респондентов старше 60 лет уверены, что российская система более справедлива, чем европейская. Однако в данной возрастной группе также больше всего респондентов, которые затрудняются с оценками степени справедливости в разных странах (40\%).

Однако сравнение уровня фактического неравенства в разных странах на основе данных Международной базы показателей неравенства (World Inequality Database WID) позволяет сделать вывод, что респонденты в РФ серьезно ошибаются в своих оценках (рис. 1). Степень фактического неравенства, измеряемая как доля доходов $1 \%$ самых обеспеченных слоев населения в \% от ВВП, с начала 1990-х гг. в РФ неуклонно 
росла, при этом в начале 2000-х она даже превысила показатели в США или Турции, в то время как в большей части стран Западной Европы и в Японии неравенство выросло, но очень незначительно (с 0,05 до 0,15 \%).
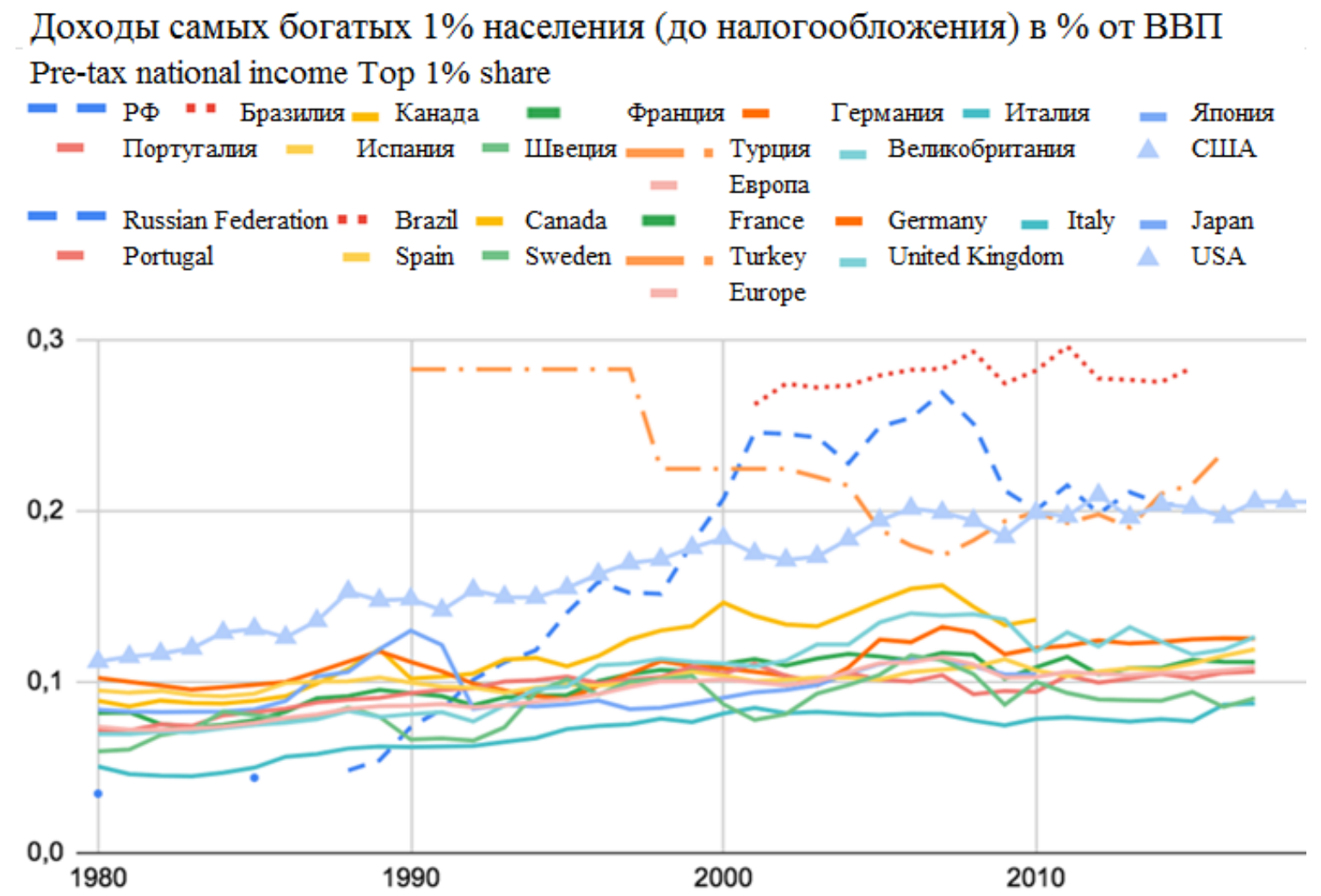

Pис. 1. Динамика доходов самых богатых (mon $1 \%$ в в некоторых странах [13]

Fig. 1. Dynamics of incomes of the richest (1\% of the population) [13]

Таким образом, на основе анализа литературы $[14,15]$ и фактических данных о показателях неравенства и субъективных оценках неравенства (восприятия неравенства) выявлена потенциальная опасность существенных расхождений в представлениях населения о неравенстве и фактическом уровне дифференциации, что в итоге оказывает влияние на востребованность государственных инструментов выравнивания результатов или обеспечения равенства возможностей, а также на оценки эффективности политики перераспределения.

Вместе с тем следует отметить практически полное отсутствие исследований, которые посвящены оценкам восприятия неравенства у старшего поколения и взаимосвязи субъективных оценок и фактических показателей неравенства, несмотря на то, что именно пожилые люди зачастую являются основными бенефициарами политики перераспределения и выступают значимой политической силой в процессе определения перспектив государственной экономической политики (стимулирование экономического роста или обеспечение социальной стабильности).

\section{Восприятие неравенства vs фактическое неравенство}

В данной работе представлены результаты оценки восприятия неравенства и проведена оценка взаимосвязи фактического и воспринимаемого неравенства среди пожилых людей (60+) в странах ЕС (22 государства) и в РФ. Использованы данные Европей- 
ского социального исследования (ESS), восьмая волна (2016). Общее количество респондентов, которые приняли участие в исследовании - более 40 тысяч человек, в том числе в РФ - 2400 респондентов, из них в возрасте старше 60 лет в ЕС - 14380, в РФ более 670 респондентов. Для оценки восприятия неравенства использовались вопросы: «В справедливом обществе различия в жизненных стандартах не должны быть большими», «Важно, чтобы люди имели равные возможности и с каждым человеком обращались одинаково», «Большая разница в доходах приемлема, если она обусловлена личными усилиями и талантами». Поскольку исходная шкала оценки предусматривает пять вариантов ответов (от «абсолютно согласен» до «абсолютно не согласен») в целях анализа переменные были сведены в бинарную форму (согласен/не согласен) и введена фиктивная переменная как сумма долей респондентов, которые согласны с первым и вторым утверждением, из которой вычтена доля респондентов, которые согласны с третьим утверждением - комплексная оценка восприятия неравенства. Результаты оценки представлены в табл. 1.

Самыми толерантными к неравенству являются пожилые люди в Чехии, комплексная оценка - 39,6. Однако в большей мере неравенство, обусловленное личными усилиями и талантами, склонны оправдывать респонденты старше 60 лет в Польше (61 \%). Не готовы мириться с высоким уровнем неравенства пожилые респонденты в Испании, Исландии и Словении.

В целом по комплексной оценке восприятия неравенства у пожилых людей РФ близка к средним значениям по странам ЕС, однако есть существенные отличия от среднеевропейских значений по уровню толерантности к неравенству, обусловленному личными усилиями и возможностями (более 20 процентных пунктов), и по оценкам равенства возможностей (более 10 процентных пунктов). По комплексной оценке восприятия неравенства РФ находится в одной группе с Австрией, Швецией, Венгрией, Норвегией, Бельгией, что свидетельствует, с одной стороны, о важности ценностей равенства и социальной солидарности в старшем возрасте, а с другой - отражает предыдущий опыт социально-экономического развития, которые оказывает влияние на восприятие текущей ситуации (шведский социализм, плановое хозяйство в РФ и Венгрии, социальная солидарность в странах с суровыми климатическими условиями). Вместе с тем высокий уровень востребованности ценностей социального равенства и справедливости среди пожилых людей в Испании и Португалии требует дальнейшего исследования (ценности фамилизма).

В целях оценки взаимосвязи ценностей равенства и солидарности с фактическими показателями неравенства и параметрами социально-экономического развития стран использовался корреляционный анализ (табл. 2). Фактическое неравенство оценивалось на основе данных World Inequality Database (2017), данных ОЭСР (S80/S20, $65+, 2018)$. Параметры социально-экономического развития оценивались на основе данных ОЭСР. Выявлены значимая сильная обратная корреляция между оценками стандартов жизни и легитимностью талантов и усилий как фактора обоснования неравенства, взаимосвязь отдельных показателей фактического неравенства, показателей неравенства и бедности, а также возрастной структуры населения. Сильная обратная статистически значимая взаимосвязь показателей фактического неравенства (Джини) и уровня жизни (GDP per capita) свидетельствует о негативном влиянии неравенства на параметры экономического благополучия в стране, что отмечено во многих российских и зарубежных исследованиях [17-20]. Взаимосвязь между фактическим неравенством и восприятием неравенства на страновом уровне - слабая и статистически незначимая. 
Таблица 1. Восприятие неравенства респондентами 60+ в странах ЕС и РФ [16] Table 1. Perceptions of inequality by $60+$ respondents in the EU and RF [16]

\begin{tabular}{|c|c|c|c|c|}
\hline $\begin{array}{c}\text { Страна } \\
\text { (Country) / } \\
\text { Восприятие } \\
\text { неравенства } \\
\text { (Inequality } \\
\text { perceptions) }\end{array}$ & $\begin{array}{c}\text { В справедливом обще- } \\
\text { стве различия в жизнен- } \\
\text { ных стандартах не } \\
\text { должны быть большими } \\
\text { («согласен»), \% } \\
\text { For fair society differ- } \\
\text { ences in standard of liv- } \\
\text { ing should be small } \\
\text { («agree») }\end{array}$ & \begin{tabular}{|c|} 
Важно, чтобы люди \\
имели равные воз- \\
можности и с каж- \\
дым человеком об- \\
ращались одинаково \\
(«согласен»), \% \\
It is important that \\
people are treated \\
equally and have equal \\
opportunities («agree»)
\end{tabular} & $\begin{array}{c}\text { Большая разница в } \\
\text { доходах приемлема, } \\
\text { если она обусловле- } \\
\text { на личными усили- } \\
\text { ями и талантами } \\
\text { («согласен»), \% } \\
\text { Large differences in } \\
\text { income acceptable to } \\
\text { reward talents and } \\
\text { efforts («agree») }\end{array}$ & $\begin{array}{c}\text { Комплексная оценка } \\
\text { восприятия нера- } \\
\text { венства («согла- } \\
\text { сен»+«согласен»- } \\
\text { «согласен»), \% } \\
\text { Comprehensive as- } \\
\text { sessment of the per- } \\
\text { ception of inequality } \\
\text { («agree»+ «agree»- } \\
\text { «agree») }\end{array}$ \\
\hline \begin{tabular}{|l|} 
Австрия \\
Austria
\end{tabular} & 73,40 & 69,10 & 39,30 & 103,20 \\
\hline \begin{tabular}{|l|} 
Бельгия \\
Belgium
\end{tabular} & 69,60 & 79,80 & 49,30 & 100,10 \\
\hline $\begin{array}{l}\text { Швейцария } \\
\text { Switzerland }\end{array}$ & 67,10 & 73,70 & 48,20 & 92,60 \\
\hline $\begin{array}{l}\text { Чехия } \\
\text { Czech }\end{array}$ & 45,70 & 51,00 & 57,10 & 39,60 \\
\hline $\begin{array}{l}\text { Германия } \\
\text { Germany }\end{array}$ & 66,10 & 73,40 & 50,70 & 88,80 \\
\hline $\begin{array}{l}\text { Эстония } \\
\text { Estonia }\end{array}$ & 63,70 & 57,20 & 50,80 & 70,10 \\
\hline $\begin{array}{l}\text { Испания } \\
\text { Spain }\end{array}$ & 80,20 & 90,10 & 29,50 & 140,80 \\
\hline $\begin{array}{l}\text { Финляндия } \\
\text { Finland }\end{array}$ & 71,50 & 74,10 & 23,90 & 121,70 \\
\hline \begin{tabular}{|l} 
Франция \\
France
\end{tabular} & 64,30 & 73,50 & 44,60 & 93,20 \\
\hline $\begin{array}{l}\text { Великобритания } \\
\text { Great Britain }\end{array}$ & 54,60 & 68,00 & 54,20 & 68,40 \\
\hline $\begin{array}{l}\text { Венгрия } \\
\text { Hungary }\end{array}$ & 58,90 & 66,70 & 17,90 & 107,70 \\
\hline $\begin{array}{l}\text { Ирландия } \\
\text { Ireland }\end{array}$ & 70,50 & 67,40 & 59,50 & 78,40 \\
\hline $\begin{array}{l}\text { Израиль } \\
\text { Israel }\end{array}$ & 68,80 & 67,00 & 41,60 & 94,20 \\
\hline \begin{tabular}{|l|} 
Исландия \\
Iceland \\
\end{tabular} & 85,40 & 75,40 & 27,10 & 133,70 \\
\hline \begin{tabular}{|l} 
Италия \\
Italy
\end{tabular} & 69,30 & 52,20 & 25,00 & 96,50 \\
\hline $\begin{array}{l}\text { Литва } \\
\text { Lithuania }\end{array}$ & 76,70 & 56,50 & 22,90 & 110,30 \\
\hline $\begin{array}{l}\text { Нидерланды } \\
\text { Netherlands }\end{array}$ & 63,50 & 84,30 & 44,30 & 103,50 \\
\hline $\begin{array}{l}\text { Норвегия } \\
\text { Norway }\end{array}$ & 69,10 & 70,90 & 39,50 & 100,50 \\
\hline $\begin{array}{l}\text { Польша } \\
\text { Poland }\end{array}$ & 61,90 & 80,80 & 61,30 & 81,40 \\
\hline $\begin{array}{l}\text { Португалия } \\
\text { Portugal }\end{array}$ & 89,20 & 64,50 & 32,80 & 120,90 \\
\hline $\begin{array}{l}\text { Швеция } \\
\text { Sweden } \\
\end{array}$ & 64,20 & 75,00 & 37,00 & 102,20 \\
\hline \begin{tabular}{|l|} 
Словения \\
Slovenia \\
\end{tabular} & 72,90 & 87,80 & 24,10 & 136,60 \\
\hline $\begin{array}{l}\text { Россия } \\
\text { Russia }\end{array}$ & 64,80 & 57,40 & 20,60 & 101,60 \\
\hline
\end{tabular}


Таблища 2. Матрица корреляций (коэффициенты коррелящии Пирсона) Table 2. Correlation matrix (Pearson correlation coefficients)

\begin{tabular}{|c|c|c|c|c|c|c|c|c|c|c|c|}
\hline $\begin{array}{c}\text { Показатели неравенства и } \\
\text { социально-экономического } \\
\text { развития } \\
\text { Inequality and socio-economic } \\
\text { performance indicators }\end{array}$ & 1 & 2 & 3 & 4 & 5 & 6 & 7 & 8 & 9 & 10 & 11 \\
\hline $\begin{array}{l}\text { 1. Стандарты жизни } \\
\text { Living standards }\end{array}$ & 1 , & ,268 &,$- 462 *$ & , 140 & ,050 &,- 226 & ,391 & ,069 & ,171 &,- 030 &,- 049 \\
\hline $\begin{array}{l}\text { 2. Равные возможности } \\
\text { Equal opportunities }\end{array}$ & & 1 & ,042 &,- 227 & -292 &,- 291 &,- 215 &,- 092 & ,274 &,- 408 &,- 157 \\
\hline $\begin{array}{l}\text { 3. Таланты и усилия } \\
\text { Talents and efforts }\end{array}$ & & & 1 &,- 127 &,- 132 &,- 019 &,- 191 &,- 228 & ,277 & ,080 &,- 031 \\
\hline $\begin{array}{l}\text { 4. Коэффициент Джини } \\
\text { Gini coefficient }\end{array}$ & & & & 1 & ,930** &, $721 * *$ &, $613^{* *}$ & ,262 &,$- 555^{* *}$ & ,600** & ,048 \\
\hline $\begin{array}{l}\text { 5.Топ } 10 \% \\
\text { Top } 10 \%\end{array}$ & & & & & 1 & ,905** & ,522* & ,070 &,$- 519 *$ & , $480^{*}$ &,- 116 \\
\hline $\begin{array}{l}\text { 6. Топ } 1 \% \\
\text { Top } 1 \% \\
\end{array}$ & & & & & & 1 & ,310 &,- 129 &,$- 447 *$ & ,338 &,- 268 \\
\hline 7. S80/S20 65+ & & & & & & & 1 & ,390 &,- 166 & ,412 & ,243 \\
\hline $\begin{array}{l}\text { 8. Средний возраст } \\
\text { Avarage age }\end{array}$ & & & & & & & & 1 &,- 417 & , 186 & ,785** \\
\hline $\begin{array}{l}\text { 9. Среднедушевой доход } \\
\text { GDP per capita }\end{array}$ & & & & & & & & & 1 &,- 385 &,- 204 \\
\hline $\begin{array}{l}\text { 10. Риск бедности, } 65+ \\
\text { Risk of poverty, } 65+\end{array}$ & & & & & & & & & & 1 & ,029 \\
\hline $\begin{array}{l}\text { 11. Доля } 65+ \\
\text { Share } 65+\end{array}$ & & & & & & & & & & & \\
\hline 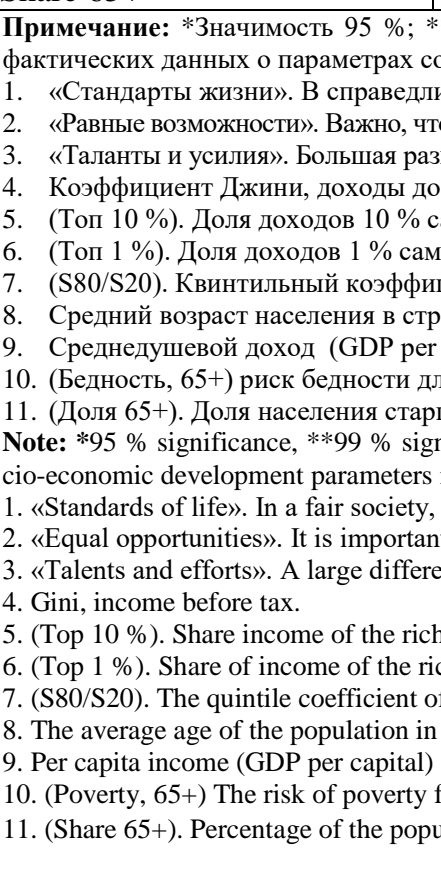 & 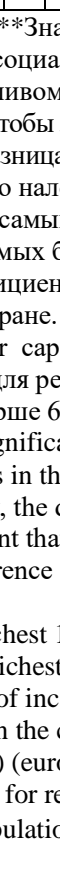 & 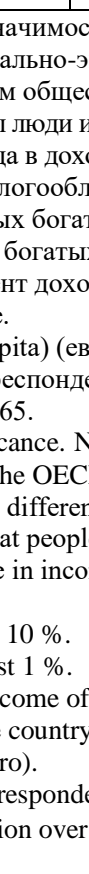 & $\begin{array}{l}\text { имели равн } \\
\text { ходах прел } \\
\text { ложения. } \\
\text { тылых. } \\
\text { Ix. } \\
\text { oдов насел } \\
\text { вро). } \\
\text { еeнтов стар } \\
\text { N=22. Israe } \\
\text { CD database } \\
\text { nces in livi } \\
\text { le have equ } \\
\text { ome is acce } \\
\text { ff the popul } \\
\text { y. } \\
\text { tents over } 6\end{array}$ & $\begin{array}{l}\text { ленлема, е } \\
\text { ления ста } \\
\text { pwe } 65 . \\
\text { sel is not i } \\
\text { se. } \\
\text { ing stand } \\
\text { eptable if } \\
\text { lation ove }\end{array}$ & $\begin{array}{l}\text { apwe } 65 . \\
\text { included in } \\
\text { lards should } \\
\text { trunities and } \\
\text { it is due to } \\
\text { er } 65 \text {. }\end{array}$ & the corr & on an & 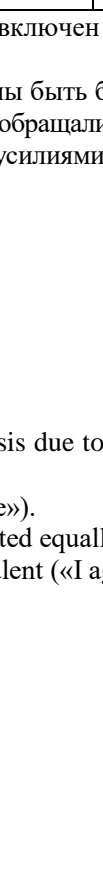 & $\begin{array}{l}\text { he lack of } \\
\text { («I agree») } \\
\text { ree»). }\end{array}$ & actual dat & ta on so- \\
\hline
\end{tabular}

Самая тесная прямая связь выявлена между стандартами жизни и квинтильным коэффициентом распределения доходов (разница в доходах 20 \% самых бедных и $20 \%$ самых богатых). Ценности равенства возможностей тесно связаны с рисками бедности для лиц старше 65 лет. Все показатели фактического неравенства демонстрируют тес- 
ную прямую связь с рисками бедности пожилых людей, что определяет важность не только инструментов государственной политики собственно в интересах старшего поколения, но и политики обеспечения равенства возможностей для населения в целом. Старение населения также связано с показателями фактического неравенства в данной группе стран, особенно тесная связь наблюдается применительно к квинтильному коэффициенту.

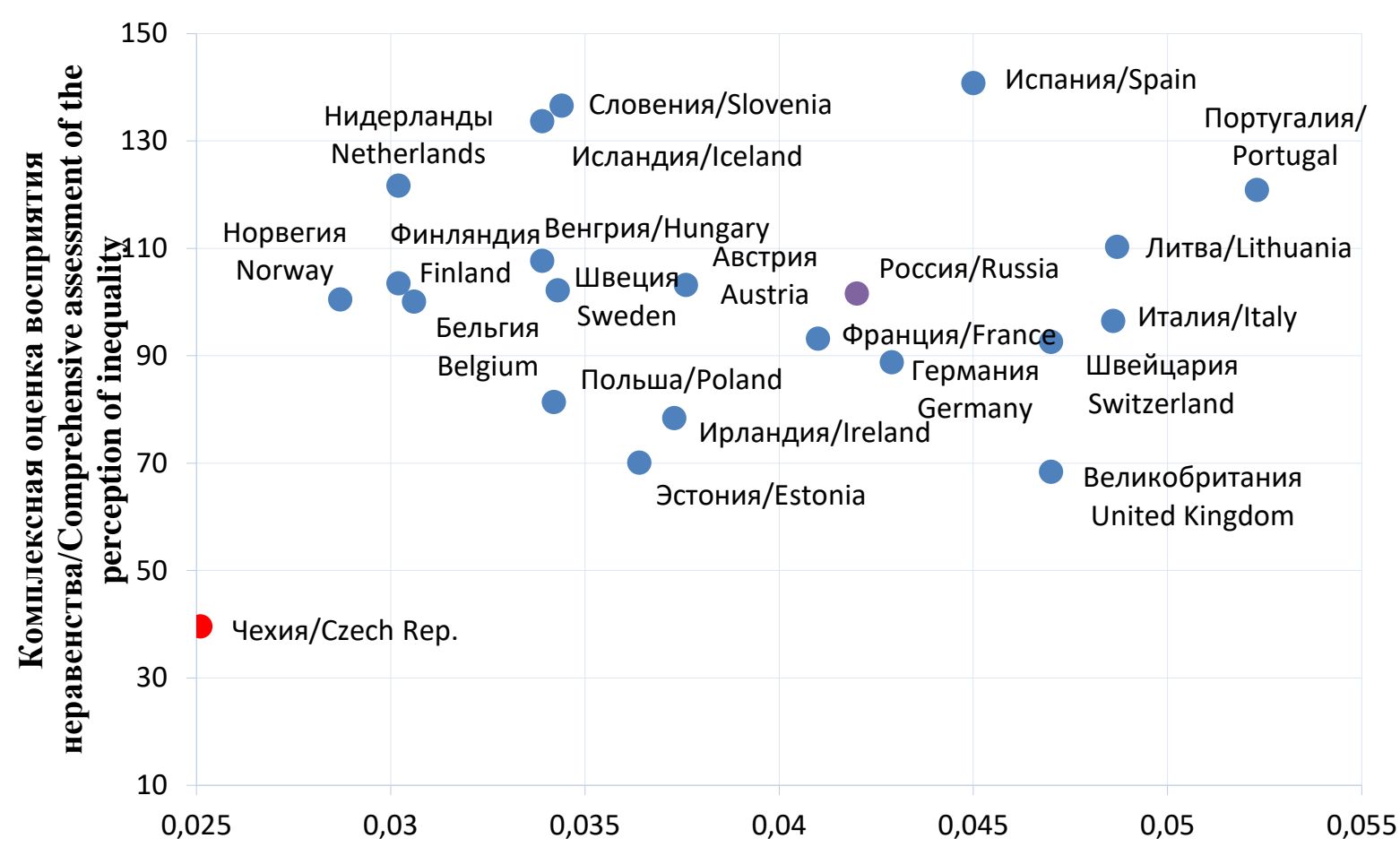

Индекс S80/S20 (65+). ОЭСP/Index S80|S20 (65+). OECD

Pис. 2. Корреляционная модель зависимости фактического и воспринимаемого неравенства

Fig. 2. Correlation model of dependence between actual and perceived inequality

Построена линейная корреляционно-регрессионная модель зависимости фактического (квинтильный коэффициент) и воспринимаемого неравенства по данной выборке стран. Не выявлена статистически значимая взаимосвязь между квинтильным коэффициентом и комплексной оценкой восприятия неравенства (рис. 2). Зависимость отдельных показателей восприятия неравенства (стандарты жизни, равенство возможностей, таланты и усилия) и квинтильного коэффициента также слабая $\left(\mathrm{R}^{2}=0,153 ; 0,046 ; 0,036\right.$ соответственно). Аналогичные результаты между показателями фактического неравенства и параметров восприятия неравенства на страновом уровне выявлены и для других показателей (коэффициент Джини, доля доходов 10 \% самых богатых и 1 \% самых богатых). Данные результаты свидетельствуют об отсутствии устойчивой связи между показателями неравенства и ценностями равенства, которые пропагандируют респонденты в странах ЕС и в РФ, что может быть обусловлено комплексом факторов: ошибочными представлениями респондентов пожилого возраста о реальном распределении доходов в стране и в мире; когнитивными проблемами, которые ограничивают возможности сравнительной оценки неравенства в разных странах; дефицитом информации о фактическом распределении доходов, которая распространяется в СМИ; закрепленны- 
ми в сознании респондентов ценностями социальной солидарности и справедливости, которые воспроизводятся вне зависимости от фактически сложившегося распределения доходов в стране.

\section{Заключение}

Проведенное исследование подтверждает результаты и выводы исследователей о наличии существенных ошибок в оценках неравенства у разных социальных групп. Показатели фактического неравенства (индекс Джини, квинтильный коэффициент распределения доходов среди респондентов старше 65 лет, доля доходов $10 \%$ и 1 \% самых богатых респондентов по отношению к ВВП страны) по странам Европейского союза слабо связаны с ценностями равенства, которые закреплены в сознании представителей старшего поколения (равенство результатов, равенство возможностей, легитимность неравенства, обусловленного личными талантами и усилиями). Причины подобного положения дел требуют дальнейшего изучения. Они могут быть связаны как с комплексом социокультурных норм и ценностей, которые заставляют представителей старшего поколения демонстрировать социально приемлемые шаблоны поведения, так и особенностями распространения информации о фактическом неравенстве и слабым интересом респондентов к этим сведениям. Гипотезы о влиянии перспектив социальной мобильности и влияние референтной группы на оценку текущего положения дел в сфере распределения доходов также требуют дополнительной проверки на выборке из респондентов 60+ лет. Сравнительный анализ различий в восприятии неравенства у пожилых и трудоспособных респондентов на страновом и индивидуальном уровне также был бы полезен. Результаты данного исследования имеют важное практическое значение в части проектирования целей и инструментов государственной политики перераспределения и укрепления социальной солидарности, запрос на которую формируется не только и не столько в зависимости от фактически сложившегося уровня неравенства, но преимущественно в зависимости от того, считается ли сложившийся уровень дифференциации доходов справедливым/легитимным. Поскольку избиратели пенсионного и предпенсионного возраста являются значимой политической силой, в процессе проектирования политических программ их интересы требуют особого внимания.

Исследование выполнено за счет гранта Российского научного фонда (проект № 19-18-00282).

\section{СПИСОК ЛИТЕРАТУРЫ}

1. Пикетти Т. Капитал в XXI веке. - М.: Ад Маргинем, 2016. - 592 с.

2. Гимпельсон В.Е., Монусова Г.А. Восприятие неравенства и социальная мобильность // Экономический журнал ВШЭ. - 2014. - Т.18. - № 2. - С. 216-248.

3. Салмина А.А. Запрос россиян на сокращение неравенства и факторы его формирования в сравнении с другими европейскими странами // Власть. - 2017. - № 2. - С.27-37.

4. Иванов В., Маркова О. Восприятие неравенства и спрос на политику перераспределения // XIX Апрельская международная научная конференция по проблемам развития экономики и общества. URL: https://conf.hse.ru/pubs/share/direct/220103399.pdf. (дата обращения 12.11.2020).

5. Gimpelson V., Treisman D. Misperceiving inequality // Economics \& Politics. - 2018. - V. 30. - № 1. P. 27-54.

6. Hauser O.P., Norton M.I. (Mis) perceptions of inequality // Current Opinion in Psychology. - 2017. V. 18. - P. 21-25.

7. Keller T., Medgyesi M., Tóth I.G. Analysing the link between measured and perceived income inequality in European countries. Research note. - 2010. - №. 8. URL: https://www.researchgate.net/publication/ 283641237_Analysing_the_link_between_measured_and_perceived_income_inequality_in_European_coun tries (дата обращения 12.11.2020). 
8. Danilova E. Actual and perceptual social inequality under transformative change in Russia and China // Europe-Asia Studies. - 2017. - V. 69. - № 1. - P. 27-52.

9. Inequalities in emerging economies: informing the policy dialogue on inclusive growth / C. Balestra, A. Llena-Nozal, F. Murtin, E. Tosetto, B. Arnaud // Inequalities in emerging economies: Informing the policy dialogue on inclusive growth. OECD Statistics Working Papers, 2018/13. URL: https://ideas.repec.org/p/oec/stdaaa/2018-13-en.html (дата обращения 12.11.2020).

10. Milanovic B. Global income inequality in numbers: in history and now // Global Policy. - 2013. - № 4 (2). P. 198-208.

11. Миланович Б. Глобальное неравенство. Новый подход для эпохи глобализации. - М.: Издательство Института Гайдара, 2017. - 336 с.

12. О справедливости и несправедливости в российском обществе. URL: https://fom.ru/TSennosti/13279 (дата обращения 12.11.2020).

13. World Inequality database. URL: https://wid.world/data/ (дата обращения 12.11.2020).

14. Мареева С.В. Справедливость и неравенство в общественном сознании россиян // Журнал институциональных исследований. - 2015. - Т. 7. - № 2. - С. 109-119.

15. Alesina A., La Ferrara E. Preferences for redistribution in the land of opportunities // Journal of public Economics. - 2005. - V. 89. - № 5-6. - C. 897-931.

16. European Social Survey. 2016. URL: https://www.europeansocialsurvey.org/data/download.html?r=8 (дата обращения: 20.01.2020)

17. Меркулова Т.В. Экономический рост и неравенство: институциональный аспект и эмпирический анализ // Мир России. Социология. Этнология. URL: https://cyberleninka.ru/article/n/ekonomicheskiyrost-i-neravenstvo-institutsionalnyy-aspekt-i-empiricheskiy-analiz (дата обращения 01.10.2020).

18. Шевяков А. Неравенство и бедность: причины и пути преодоления существующих диспропорций // Индекс. URL: http://index.org.ru/journal/21/shev21.html (дата обращения 01.10.2020).

19. Adams R.H. Economic growth, inequality and poverty: findings from a new data set. - World Bank Publications, 2003. URL: https://openknowledge.worldbank.org/handle/10986/19109 (дата обращения: 01.10.2020).

20. Levin J., Bigsten A. Growth, income distribution, and poverty: a review. URL: https://www.researchgate.net/publication/5094687_Growth_Income_Distribution_and_Poverty_A_Review (дата обращения: 01.10.2020).

Поступила 12.12.2020 2. 


\title{
COMPARATIVE ANALYSIS OF INCOME INEQUALITY PERCEPTIONS BY THE ELDERLY IN EUROPE AND RUSSIA: THE RELATIONSHIP BETWEEN ACTUAL AND PERCEIVED INCOME INEQUALITY
}

\author{
Elena A. Frolova ${ }^{1,2}$, \\ frolova_ea@mail.tsu.ru \\ Elmira R. Kashapova², \\ elmira@tpu.ru \\ Veronika A. Malanina², \\ milanskaya@mail.ru \\ Fabio Casati2, \\ kasati@tpu.ru \\ ${ }^{1}$ National Research Tomsk State University, \\ 36, Lenin avenue, Tomsk, 634050, Russia. \\ 2 National Research Tomsk Polytechnic University, \\ 30, Lenin avenue, Tomsk, 634050, Russia.
}

Elena A. Frolova, Dr. Sc., professor, National Research Tomsk State University; leading researcher, National Research Tomsk Polytechnic University.

Elmira R. Kashapova, junior researcher, National Research Tomsk Polytechnic University.

Veronika A. Malanina, Cand. Sc., associate professor, National Research Tomsk Polytechnic University.milanskaya@mail.ru

Fabio Casati, Ph.D, leading researcher, National Research Tomsk Polytechnic University.

The article describes the attitude of the population to inequality by the elderly in European countries and Russia. The relevance of the study is caused by the to differences in the perception of inequality and its actual indicators, which affects the demand for state equalization policy tools, especially for older adults. The purpose of this study is to assess the relationship between actual and perceived inequality among the older generation in the EU and the Russian Federation. Methods. We have used the method of descriptive statistics on the samples of the $8^{\text {th }}$ wave of the European social research (ESS-2016) for the age group of 60+ years in Russia and European countries. Data from the World Inequality Database (2017) and data from the OECD (2018) were used to assess actual inequality. Correlation analysis is used for assessment of the relationship between subjective and actual inequality indicators. Results. A comprehensive assessment of the perception of inequality among older people in the Russian Federation is close to the average values for EU countries. However, there are differences from the European average in the level of tolerance to inequality due to personal effort and opportunities, and in estimates of equality of opportunity. Correlations between actual and subjective indicators of inequality showed that there is an inverse correlation between estimates of living standards and the legitimacy of talent and effort, the Gini coefficient and the standard of living indicator (GDP per capital). Indicators of actual inequality showed a close direct relationship with the risks of poverty of older people. There is no statistically significant relationship between income differentiation and a comprehensive assessment of the perception of inequality.

Key words: Income inequality, older adults, actual inequality, perceived inequality, EU, Russia.

The study was supported by the Russian Science Foundation (project no. 19-18-00282). 


\section{REFERENCES}

1. Piketti T. Kapital v XXI veke [Capital in the twenty-first century]. Moscow, Ad Marginem Publ., 2016. $592 \mathrm{p}$.

2. Gimpelson V.E., Monusova G.A. Vospriyatie neravenstva i sotsialnaya mobilnost [Perception of inequality and social mobility]. Ekonomicheskiy zhurnal VShE, 2014, vol. 18, no. 2, pp. 216-248.

3. Salmina A.A. Zapros rossiyan na sokrashchenie neravenstva i faktory ego formirovaniya $v$ sravnenii s drugimi evropeyskimi stranami [Attitudes of the Russians towards income inequality and factors of their formation in comparison with other European countries]. Vlast, 2017, no. 2, pp. 27-37.

4. Ivanov V., Markova O. Vospriyatie neravenstva i spros na politiku pereraspredeleniya [Perceptions of inequality and demand for redistributive policies]. XIX Aprelskaya mezhdunarodnaya nauchnaya konferentsiya po problemam razvitiya ekonomiki i obshchestva [XIX April international scientific conference on the problems of economic and social development]. Available at: https://conf.hse.ru/pubs/share/ direct/220103399.pdf (accessed 12 November 2020).

5. Gimpelson V., Treisman D. Misperceiving inequality. Economics \& Politics, 2018, vol. 30, no. 1, pp. $27-54$.

6. Hauser O.P., Norton M.I. (Mis) perceptions of inequality. Current Opinion in Psychology, 2017, vol. 18, pp. 21-25.

7. Keller T., Medgyesi M., Tóth I. G. Analysing the link between measured and perceived income inequality in European countries. Research note, 2010, no. 8. Available at: https://www.researchgate.net/ publication/283641237_Analysing_the_link_between_measured_and_perceived_income_inequality_in_European_ countries (accessed 12 November 2020)

8. Danilova E. Actual and perceptual social inequality under transformative change in Russia and China. Europe-Asia Studies, 2017, vol. 69, no. 1, pp. 27-52.

9. Balestra C., Llena-Nozal A., Murtin F., Tosetto E., Arnaud B. Inequalities in emerging economies: Informing the policy dialogue on inclusive growth. OECD Statistics Working Papers. 2018/13. Available at: https://ideas.repec.org/p/oec/stdaaa/2018-13-en.html (accessed 12 November 2020).

10. Milanovic B. Global income inequality in numbers: in history and now. Global Policy, 2013, no 4 (2), pp. 198-208.

11. Milanovich B. Globalnoe neravenstvo. Novy podkhod dlya epokhi globalizatsii [Global inequality. A new approach for the age of globalization]. Moscow, Gaidar Institute Publ. House, 2017. 336 p.

12. O spravedlivosti i nespravedlivosti v rossiyskom obshchestve [About justice and injustice in Russian society]. Available at: https://fom.ru/TSennosti/13279 (accessed 12 November 2020).

13. World Inequality database. Available at: https://wid.world/data/ (accessed 12 November 2020).

14. Mareeva S.V. Spravedlivost i neravenstvo v obshchestvennom soznanii rossiyan [Social justice and inequalities in view of the Russians]. Journal of Institutional studies, 2015, vol. 7, no. 2, pp. 109-119.

15. Alesina A., La Ferrara E. Preferences for redistribution in the land of opportunities. Journal of public Economics, 2005, vol. 89, no. 5-6, pp. 897-931.

16. European Social Survey. 2016. Available at: https://www.europeansocialsurvey.org/data/download. html?r=8 (accessed 20 January 2020).

17. Merkulova T.V. Ekonomicheskiy rost i neravenstvo: institutsionalny aspekt i empiricheskiy analiz [Economic growth and inequality: institutional aspect and empirical analysis]. Mir Rossii. Sotsiologiya. Etnologiya. Available at: https://cyberleninka.ru/article/n/ekonomicheskiy-rost-i-neravenstvoinstitutsionalnyy-aspekt-i-empiricheskiy-analiz (accessed 1 October 2020).

18. Shevyakov A. Neravenstvo i bednost: prichiny i puti preodoleniya sushchestvuyushchikh disproportsiy [Inequality and poverty: causes and ways to overcome existing disparities]. Available at: http://index.org.ru/journal/21/shev21.html (accessed 1 October 2020).

19. Adams R.H. Economic growth, inequality and poverty: findings from a new data set. World Bank Publications. 2003. Vol. 2972. Available at: https://openknowledge.worldbank.org/handle/10986/19109 (accessed 1 October 2020).

20. Levin J., Bigsten A. Growth, income distribution, and poverty: a review. Available at: https://www.researchgate.net/publication/5094687_Growth_Income_Distribution_and_Poverty_A_Review (accessed 1 October 2020). 